\title{
Redox-linked conformation change and electron transfer between monoheme $c$-type cytochromes and oxides
}

\author{
Nidhi Khare a, David M. Lovelace a, Carrick M. Eggleston ${ }^{\mathrm{a}, *}$, Michael Swenson ${ }^{\mathrm{b}}$, \\ Timothy S. Magnuson ${ }^{b}$ \\ a Department of Geology and Geophysics, University of Wyoming, Laramie, WY 82071, USA \\ b Department of Biological Sciences, Idaho State University, Pocatello, ID 83204, USA
}

Received 12 September 2005; accepted in revised form 15 June 2006

\begin{abstract}
Electron transfer between redox active proteins and mineral oxides is important in a variety of natural as well as technological processes, including electron transfer from dissimilatory metal-reducing bacteria to minerals. One of the pathways that could trigger electron transfer between proteins and minerals is redox-linked conformation change. We present electrochemical evidence that mitochondrial cytochrome $c$ (Mcc) undergoes significant conformation change upon interaction with hematite and indium-tin oxide (ITO) surfaces. The apparent adsorption-induced conformation change causes the protein to become more reducing, which makes it able to transfer electrons to the hematite conduction band. Although Mcc is not a protein thought to be involved in interaction with mineral surfaces, it shares (or can be conformed so as to share) some characteristics with multiheme outer-membrane cytochromes thought to be involved in the transfer of electrons from dissimilatory iron-reducing bacteria to ferric minerals during respiration. We present evidence that a $10.1 \mathrm{kDa}$ monohoeme cytochrome isolated and purified from Acidiphilium cryptum, with properties similar to those of Mcc, also undergoes conformation change as a result of interaction with hematite surfaces.
\end{abstract}

(c) 2006 Elsevier Inc. All rights reserved.

\section{Introduction}

Globular proteins such as mitochondrial cytochrome $c$ (Mcc) are polypeptide chains folded such that hydrophobic amino acid residues are positioned in the interior of the molecule and the hydrophilic residues coat the exterior. Folding endows the molecule with particular electrostatic properties (such as positively and negatively charged exterior "patches"), a particular dielectric environment around internal redox cofactors, and serves to present particular functional ligands to these cofactors (such as to $\mathrm{Fe}$ in hemes) within the protein. Changes in folding (conformation change) often thus result in changes in all of these other properties.

\footnotetext{
${ }^{*}$ Corresponding author. Fax: +1 3077666679.

E-mail address: carrick@uwyo.edu (C.M. Eggleston).
}

The function of redox proteins is often to act as energy transducers in which conformational change is transformed into electrochemical energy. An example of this is found in cytochrome $c d_{1}$ nitrite reductase (Williams et al., 1997), in which ligand-switching by the $d$-heme of the protein is mechanically linked to ligand-switching by the $c$-heme so as to control not only the redox state of the $c$-heme but also the timing of electron transfer from the $c$-heme to the $d$-heme during the catalytic cycle.

The forces of adsorption affect protein conformation and therefore also redox properties. For example, it had been thought for decades that interaction of Mcc with metal or graphite electrodes resulted in protein denaturation and thus a lack of electrochemical response. However, direct electrochemistry was then demonstrated after a metal electrode was coated with 4,4'-bipyridine (Eddowes and Hill, 1977) as well as using conductive indium-doped tin oxide electrodes (Yeh and Kuwana, 1977). Specific interactions between protein and the electrode surface were 
thought to limit unfolding in these cases, and oxide electrodes were thus established as a favorable electrode material. In general, the extent to which a redox protein such as cytochrome $c$ unfolds or denatures when it interacts with an electrode depends on the nature of the surface (Fig. 1). Are the adsorption forces large enough to overcome the forces that hold the protein in a particular conformational state? If so, what conformational state is adopted instead? Far from necessarily representing "denaturation", conformation change can be key to protein operation; the physiological role of Mcc is to shuttle electrons from the mitochondrial $b c_{1}$ complex to cytochrome $c$ oxidase (e.g., Lange and Hunte, 2002), and there is evidence that interaction between Mcc and its physiological partners triggers conformational change that results in changed redox properties (Witt et al., 1998; Cruciat et al., 2000; Dick et al., 2000). It is reasonable to expect that interaction of such a protein with a mineral particle may also trigger conformation change with redox consequences, and the phenomenon of redox-linked conformation change is thus the subject of interest here.

The chemical pathways by which dissimilatory iron-reducing bacteria (DIRB) transfer electrons to solid mineral electron accepters is a subject of increasing research interest. One of the several possible ways that DIRB are thought to transfer electrons to ferric iron (hydr)oxides is through direct mineral surface-protein interaction using cytochrome proteins emplaced on the outer surface of the outer cell membrane and connected to a "molecular wire" system that transports electrons through the Gram-negative cell membranes (e.g., Myers and Myers, 1993, 1997, 2002, 2003; Gaspard et al., 1998; Beliaev and Saffarini, 1998; Magnuson et al., 2001; Richardson, 2000; Pitts et al., 2003; Mehta et al., 2005). DiChristina et al. (2002) found a secretion system that is a likely pathway for emplacement of redox molecules to the outer surface of the outer membrane.

One way in which electron transfer to mineral surfaces could be controlled is through adsorption-induced confor-
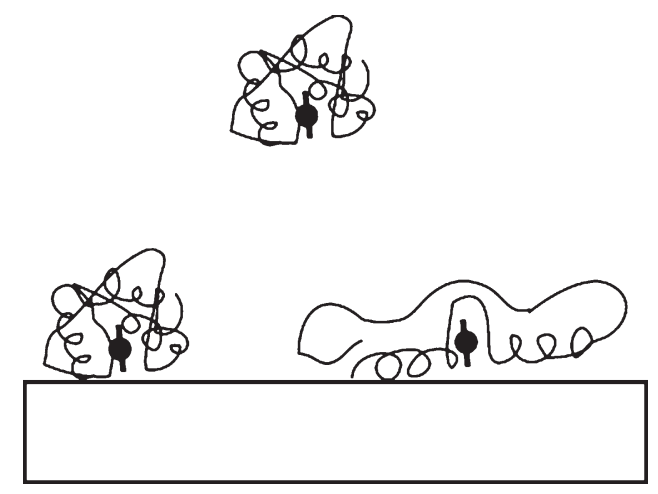

Fig. 1. Illustration of possible consequences of adsorption; in one case, the protein may adsorb with little conformation change and therefore with little change in redox properties, but in the other case adsorption may cause substantial conformation change that results in substantial changes in redox properties. mation change that in turn changes the redox properties of the protein to favor protein-to-mineral electron transfer. DIRB are now thought to participate in redox cycling of iron in the oceans, sediments, and soils (Lovley, 1991, 2002), and thus their biochemical mode of interaction with minerals is of interest. This is true not only for a better understanding of global biogeochemical redox cycling, but also in bioremediation strategies that make use of DIRB to reductively immobilize or inhibit the migration of $\mathrm{U}, \mathrm{Tc}, \mathrm{Np}, \mathrm{Cr}$, and other metals (e.g., Albrechtsen and Christensen, 1994; Lovley and Phillips, 1994; Lloyd et al., 2000, 2002; Liu et al., 2002; Cummings et al., 2003).

Mcc is clearly not involved in bacterial iron reduction. However, it is one of the most thoroughly studied redox proteins. It was first isolated and purified in 1925 (Keilin, 1925), and its structure and properties have been extensively studied since then. Mcc serves as a "Guinea pig" or a comparative baseline for many studies of other redox proteins, and its interaction with iron oxide is thus an important preliminary step in the study of the interaction of outer membrane proteins from DIRB with iron oxides. In particular, Mcc structure and folding states have been linked to specific optical absorption and electrochemical markers (e.g., Thomas et al., 2000) that allow us to correlate relatively simple optical or electrochemical observations with the conformational state of the protein while adsorbed to a solid surface (a situation for which no direct structural information is available). This is not yet possible with outer-membrane proteins from DIRB.

Here, we present electrochemical evidence that hematite and indium-tin oxide electrodes become coated with unfolded Mcc while in contact with Mcc solutions (we used the indium-tin oxide electrodes to provide a comparative connection between our work with hematite electrodes and earlier work with Mcc and indium-tin-oxide electrodes; e.g., Bowden et al., 1984). Unfolded Mcc is more reducing than is native $\mathrm{Mcc}$, and we show that adsorption of native Mcc in the reduced form can result in electron transfer from Mcc to hematite. This demonstrates that adsorption-induced conformation change can trigger electron transfer, and thus that similar conformationally triggered electron transfer is a possibility in the case of outer-membrane proteins from DIRB as well. Finally, we demonstrate that a monoheme $c$-type cytochrome from Acidiphilium cryptum exhibits at least 3 different reduction potentials when interacting with a hematite electrode. In the absence of major impurities in the protein preparation, this demonstrates that at least 3 different conformational states probably exist when this protein interacts with oxide electrodes.

Larger, multiheme outer-membrane cytochromes from DIRB present much greater redox and conformational complexity, and therefore are likely to behave differently from the proteins studied here. Nevertheless, our results show that the general phenomenon of redox-linked conformation change must be considered as part of understanding how the outer-membrane cytochromes operate. 


\section{Methods}

\subsection{Hematite electrodes}

Hematite $\left(\alpha-\mathrm{Fe}_{2} \mathrm{O}_{3}\right)$ from Tarascon sur Ariège, France was used as a working electrode in electrochemical experiments. Preparation of these natural crystals for use as electrodes is described in Eggleston et al. (2003) and Stack et al. (2004). This hematite has an electron donor impurity concentration (mostly Sn and Ti) of about $2.0 \times 10^{-3}$ atom $\%$ based on ICP-MS analyses (Eggleston et al., 2003).

\section{2. $M c c$}

Mitochondrial horse heart cytochrome $c$ (PDB ID: 1hrc) was obtained from Sigma and used without further purification. Mcc is water-soluble, and a $10^{-4} \mathrm{M}$ Mcc stock solution was prepared in $100 \mathrm{mM} \mathrm{KCl}$. We prepared a solution of roughly 50:50 reduced and oxidized Mcc by adding a solution of $10^{-3} \mathrm{M}$ sodium dithionite dropwise to $1 \mathrm{ml}$ of $10^{-4} \mathrm{M}$ Mcc to a total added volume of $1.75 \mathrm{ml}$

The amino acid content, basic conformational states, redox potentials, and isoelectric point ( $\mathrm{pH}$ 10) of Mcc were known prior to 1941 (e.g., Theorell and Akesson, 1941a,b,c,d). Mcc is illustrated in Fig. 2. Four lysines are grouped around the heme edge of the molecule, forming a positively charged "edge" that is optimized for electrostatic interaction with negatively charged portions of physiologic partners or of surfaces (Margoliash et al., 1973; Chen et al., 2002; Dick et al., 2000). Heme Fe is axially coordinated by histidine 18 and methionine 80 and maintained in the low-spin state. Breaking the relatively weak $\mathrm{Fe}-\mathrm{S}$ (methionine) bond leads to switching to the high spin state, and allows a portion of the polypeptide (from residue 78 to residue 90) to move away from the heme and expose the heme to a more aqueous environment that promotes electron transfer (e.g., Pinheiro, 1994; Tezcan et al., 1998).

We use the term "unfold" rather than the term "denature" because the term "denature" implies irreversible loss of catalytic activity. Some interpret this to mean loss of redox activity, which is not the case here. It is

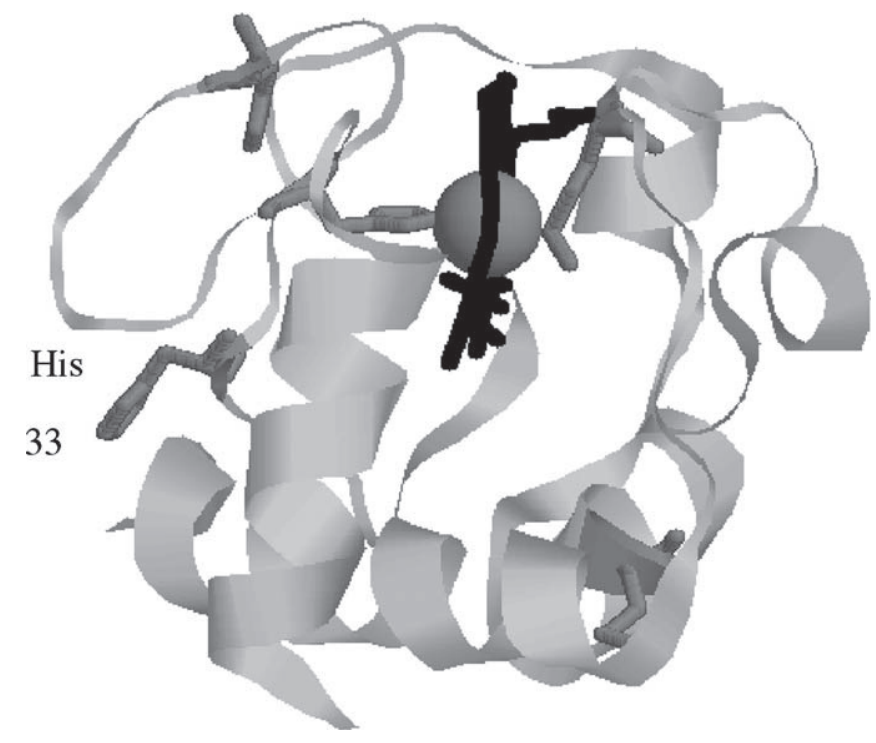

Fig. 2. RASMOL rendering of Mcc (PDB ID: 1hrc) in which the polypeptide is light gray except for methionine residues (darker gray, stick rendering, to the right of the heme) and histidine residues (darker gray, stick rendering, to the left of the heme). Heme is black (stick rendering), $\mathrm{Fe}$ is a dark gray sphere. The $\mathrm{Fe}$ of the heme is coordinated by histidine 18 and methionine 80 , but another histidine (histidine 33, labeled) can substitute for methionine 80 in some conformations (e.g., Thomas et al., 2000). also not clear that the changes in redox properties encountered here are necessarily irreversible.

\subsection{The $10.1 \mathrm{kDa}$ cytochrome from Acidiphilium cryptum}

The following procedures were necessary in order to isolate and purify a $10.1 \mathrm{kDa}$ cytochrome from Acidiphilium cryptum for use in the experiments reported here. A. cryptum strain JF-5 was obtained from K. Kusel (University of Bayreuth) and was cultured for cytochrome production using a modified mineral salts medium. Cells were grown in liquid media containing (per liter) $0.5 \mathrm{~g}$ tryptic soy broth, $5 \mathrm{ml}$ vitamin solution, $5 \mathrm{ml}$ mineral solution, $1 \mathrm{~g}\left(\mathrm{NH}_{4}\right)_{2} \mathrm{SO}_{4}, 0.01 \mathrm{~g} \mathrm{KCl}, 0.05 \mathrm{~g} \mathrm{~K}_{2} \mathrm{HPO}_{4}, 0.25 \mathrm{~g}$ $\mathrm{MgSO}_{4}, 0.1 \%$ glucose and $0.03 \%$ yeast extract. Cells were grown in $10 \mathrm{~L}$ carboys at a $\mathrm{pH}$ of 3.2 for $24 \mathrm{~h}$ under aerobic conditions, after which oxygen addition was stopped and $10 \mathrm{mM}$ ferric sulfate was added as an electron acceptor. After $48 \mathrm{~h}$ cells were subjected to aerobic conditions for an additional $24 \mathrm{~h}$ and harvested by centrifugation $(6000 \mathrm{~g})$. Cell pellets were washed twice with $20 \mathrm{mM}$ citric acid buffer $\mathrm{pH} 3.0$ and stored at $-20{ }^{\circ} \mathrm{C}$. Outer membrane extraction buffer [OME; $20 \mathrm{mM}$ citric acid buffer $\mathrm{pH} 3.0$ containing $2 \% 3$-( $N, N$-dimethylmyristyl-ammonio)propanesulfonate (Zwittergent 3-14) and $60 \mathrm{mM}$ NaEDTA] was added to frozen cell pellets at $3.5 \mathrm{ml} / \mathrm{g}$ cells. Cells were incubated in the OME buffer for $24 \mathrm{~h}$ at $4{ }^{\circ} \mathrm{C}$, after which the cell suspension was centrifuged at $8000 \mathrm{~g}$ and the supernatant was retained as the crude protein fraction. The lysis buffer/protein extraction was repeated 6 times.

The crude protein mixture was desalted against Buffer A $(20 \mathrm{mM}$ citric acid containing $1.5 \%$ Zwittergent 3-14) using a HiPrep ${ }^{\mathrm{TM}}$ desalting column (Amersham Biosciences Corp., Piscataway, NJ). The crude fraction was then run on a HiPrep ${ }^{\text {TM }}$ 16/10 SP FF ion exchange column (Amersham Biosciences Corp., Piscataway, NJ) equilibrated with buffer A and eluted with a linear gradient of $0-1 \mathrm{M} \mathrm{NaCl}$ in the same buffer. Fractions were pooled based on $A_{409}$ (Soret band absorption). Pooled fractions were then run on sodium dodecyl sulfate-polyacrylamide gel electrophoresis (SDSPAGE) gels that were subsequently heme stained (Thomas et al., 1976) Fractions containing the $10.1 \mathrm{kDa}$ cytochrome $c$ were diluted with an equal volume of buffer A, concentrated on the same SP column and eluted with $1 \mathrm{M} \mathrm{NaCl}$. The concentrated fraction was run on a HiPrep ${ }^{\text {TM }}$ 26/60 Sephacryl ${ }^{\text {TM }}$ S-200 High Resolution size exclusion column (Amersham; see above) equilibrated with buffer A containing $0.5 \mathrm{M} \mathrm{NaCl}$ at a flow rate of $1.5 \mathrm{ml} / \mathrm{min}$. Cytochrome containing fractions $\left(A_{409}\right)$ were pooled and desalted on a HiPrep ${ }^{\mathrm{TM}}$ desalting column (Amersham, see above) against buffer A. As a final polishing step the $10.1 \mathrm{kDa}$ cytochrome was resolved on a UNO ${ }^{\text {TM }} \mathrm{S} 1$ ion exchange column (Bio-Rad Laboratories, Hercules, CA) and eluted with a linear gradient of $0.25-0.75 \mathrm{M} \mathrm{NaCl}$ in buffer A. SDS-PAGE was used to confirm protein purity (Schagger and von Jagow, 1987). Spectroscopic characterization was carried out with a Shimadzu UV-2401 spectrophotometer.

Based on a draft genome sequence (www.jgi.doe.gov) and biochemical studies, this cytochrome is a monoheme $c$-type cytochrome with histidinemethionine axial coordination and is thus similar in size and redox properties to Mcc. This protein is part of the electron transport chain of an acidiphilic iron-reducing organism, but it is not clear that it is necessarily involved in direct $\mathrm{Fe}(\mathrm{III})$ reduction. Nevertheless, this cytochrome is the most comparable to Mcc of the available cytochromes from a DIRB species, and thus affords a relatively close comparison.

The protein was buffer exchanged into MOPS at $\mathrm{pH} 7$ using YM-10 Microcon spin columns. The protein started at roughly $0.7 \mathrm{mg} \mathrm{mL}^{-1}$. Based on Soret band optical absorption, the final concentration after buffer exchange was similar to the starting concentration. We did not measure the protein content of the solutions after buffer exchange, however, so as to preserve as much as possible of the small amounts of available protein for use in experiments.

\subsection{Voltammetry}

Cyclic voltammetry (CV) and differential pulse voltammetry (DPV) were used in this work. In CV, a linear potential ramp is applied at a specified rate and the resulting current is recorded as a function of 
potential (conditions are given in the figure captions). Because we were working with oxide semiconductor electrodes, some of the observed current is due to capacitive charging and discharging of the space charge layer (e.g., see Boschloo and Fitzmaurice, 1999). The capacitive current can swamp or obscure currents from protein redox reduction and oxidation, especially when these currents are small. For this reason, we use differentiation of $\mathrm{CV}$ scans to locate the positions of reduction and oxidation peaks. We also used DPV as a way of excluding purely capacitive current transients so as to observe mainly currents arising from protein reduction (we performed only cathodic DPV scans). In DPV, a voltage pulse is applied for a short time after which the potential returns to a new value incremented from the preceding voltage and the current is recorded. The idea is that capacitive current transients take place during the voltage pulse, before the current is recorded. DPV parameters are given in the figure captions.

Voltammetric experiments were conducted using hematite or ITO working electrodes, a platinum counter electrode, and an $\mathrm{Ag} / \mathrm{AgCl}$ reference electrode constructed from a silver wire (oxidized in $3 \mathrm{M} \mathrm{KCl}$ ) placed in a glass capillary tube with a platinum leak-plug at the end. The tube was filled with $3 \mathrm{M} \mathrm{KCl}$, and the electrode was tested against a commercial $\mathrm{Ag} / \mathrm{AgCl}$ reference electrode. The capillary $\mathrm{Ag} / \mathrm{AgCl}$ reference electrode always tested within $25 \mathrm{mV}$ positive of the commercial reference electrode. This discrepancy was quite consistent and was corrected for; we found it acceptable given the resulting ability to work with electrochemical cell volumes of only a few $\mathrm{mL}$, allowing us to work with small amounts of protein. We use $E^{0^{\prime}}$ to denote midpoint potential, which may differ from a standard potential $\left(E^{0}\right)$.

The electrochemical cell was stirred and purged of oxygen using flowing ultra high purity nitrogen gas. $\mathrm{CV}$ was performed using a $\mathrm{CH}$ Instruments $900 \mathrm{~B}$ bipotentiostat controlled from a PC. Cleaned hematite crystals were attached to a metal clip and suspended in the solution of interest. The CV results are not unique to a particular crystal face, and currents vary from experiment to experiment because the solution contact area is different in each case. The fragile crystals frequently broke while changing solutions, adding to problems comparing currents from experiment to experiment. In this study, we therefore focus on the positions of redox waves rather than currents.

\subsection{ITO electrodes}

Indium doped tin oxide (ITO) refers to a material that is $90 \mathrm{~mol} \%$ $\mathrm{In}_{2} \mathrm{O}_{3}$ and $10 \mathrm{~mol}^{\%} \mathrm{SnO}_{2}$ and is conductive and transparent to visible light. ITO was obtained from Delta Technologies, Ltd. (Stillwater, Minnesota) as a film on a quartz backing and used after cleaning as described in Bowden et al. (1984).

\section{Results and discussion}

\subsection{Electrochemistry of $\mathrm{Mcc}$ using $\alpha-\mathrm{Fe}_{2} \mathrm{O}_{3}$ (hematite) electrodes}

Previous electrochemical work using hematite electrodes in solutions containing Mcc (Eggleston et al., 2005) produced voltammograms with redox waves giving an $E^{0^{\prime}}$ of about $+70 \mathrm{mV}$ vs. $\mathrm{Ag} / \mathrm{AgCl}$. This is the $E^{0^{\prime}}$ expected of native Mcc (Chen et al., 2002; Xu et al., 2004) and in agreement with earlier observations for $\mathrm{Mcc}$ on $\mathrm{SnO}_{2}$ electrodes as well (Yeh and Kuwana, 1977).

Although the initial CV work is in agreement with earlier work using oxide electrodes in suggesting that Mcc retains native conformation when interacting with oxides, subsequent repeat experiments sometimes showed no (or very faint) redox peaks, introducing a disquieting lack of consistency from experiment to experiment. This behavior is reminiscent of observations by Hill et al. (1997) for glassy carbon electrodes in which redox peaks due to Mcc tend to disappear with successive CV scans over a period of seconds. Hill et al. (1997) attributed this to a self-blocking mechanism in which protein sorbs to the electrode and blocks the electrode from subsequent interaction with further Mcc from solution.

As shown by Chen et al. (2002), the reduction potential or $E^{0^{\prime}}$ observed using direct electrochemistry is characteristic of the specific state of the protein. At hematite electrodes, native Mcc has a cathodic peak potential $\left(E_{\mathrm{pc}}\right)$ of about $-100 \mathrm{mV}$ and an anodic peak potential $\left(E_{\mathrm{pa}}\right)$ of about $+240 \mathrm{mV}$ vs $\mathrm{Ag} / \mathrm{AgCl}$ (resulting in an $E^{0^{\prime}}$ of about $+70 \mathrm{mV}$; Eggleston et al., 2005). This difference between reduction and oxidation waves is much larger than the $60 \mathrm{mV}$ required of a fully reversible redox couple, implying that Mcc redox processes are not fully reversible at the hematite electrode. Concentrating on cathodic waves because they have proven the easiest to observe and differentiate (and because positive band bending at positive potentials leads to blocking of the hematite electrode by the space charge layer), Chen et al. (2002) find that unfolding of Mcc can result in a shift in $E_{\mathrm{pc}}$ to about $-400 \mathrm{mV}$ vs. $\mathrm{Ag} / \mathrm{AgCl}$. This potential is characteristic of both bis-his coordinated heme (Tezcan et al., 1998) and water coordinated heme (Pilloud et al., 2000) so we cannot easily distinguish between these two coordination possibilities. Nevertheless, it is well-established that this shift in $E_{\mathrm{pc}}$ indicates a substantial conformation change or unfolding of the protein (Hildebrandt and Stockburger, 1989; Moore and Pettigrew, 1990; Oellerich et al., 2002; Pettigrew and Moore, 1987).

An example of a $\mathrm{CV}$ with no obvious reduction waves is found in Fig. 3a, along with a differential plot of a portion of the cathodic scan (Fig. 3b). Fig. 3b reveals faint reduction waves at about $-120 \mathrm{mV}$ and about $-420 \mathrm{mV}$, characteristic of native and unfolded Mcc respectively. This can be compared to a derivative of the cathodic scan from a CV from Eggleston et al. (2005) in which no evidence of a reduction wave at about $-400 \mathrm{mV}$ is detected (Fig. 3c). Again, there is clearly variability between experimental results, for which explanations are suggested later.

Fig. 4 shows a CV, and Fig. 5 gives a DPV, showing reduction waves near $-400 \mathrm{mV}$, characteristic of unfolded Mcc interacting with the hematite electrode. In order to test whether such negative reduction potentials can be attributed to unfolded Mcc, we followed Thomas et al. (2000) and used a denaturant to deliberately unfold the protein. Thomas et al. (2000) used optical absorption spectroscopies, circular dichroism (CD) and magnetic circular dichroism (MCD) to monitor the unfolding of both the oxidized and reduced forms of Mcc with added guanidine $\mathrm{HCl}$ (abbreviated $\mathrm{GuHCl}$ ). They found, for oxidized Mcc, that with an increase in $\mathrm{GuHCl}$ concentration to $1 \mathrm{M}$, a bis-histidine (bis-his) coordinated heme Fe within a globular intermediate folding state is found involving histidine 33 (Fig. 2). Further addition of $\mathrm{GuHCl}$ to $3 \mathrm{M}$ results in further unfolding to a non-globular state that 

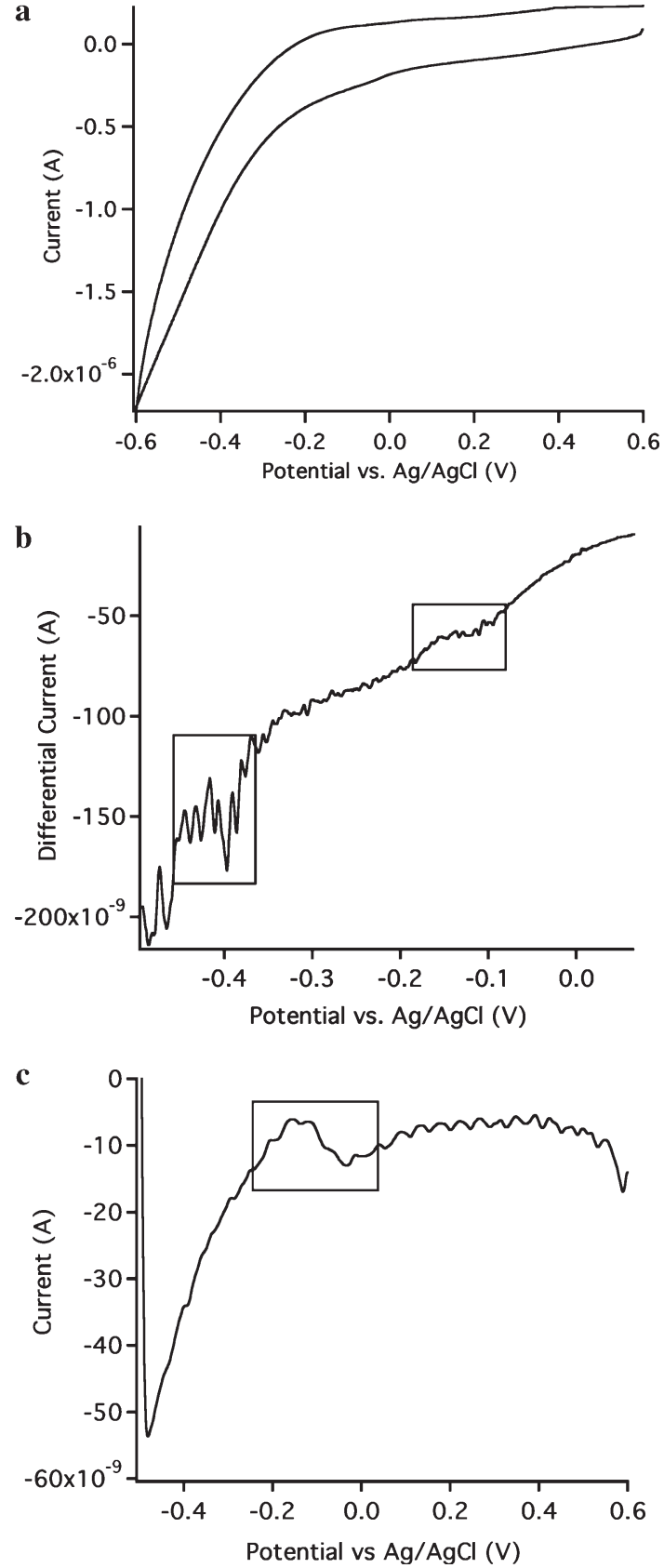

Fig. 3. (a) A CV of a $10^{-4} \mathrm{M} \mathrm{Mcc}, 100 \mathrm{mM} \mathrm{KCl}$ solution using a hematite electrode ( $\mathrm{pH}$ 7.0). Redox waves are present but not obvious. (b) A differential plot of a portion of the negative-going (lower) scan of (a) showing a small derivative peak at $\sim-120 \mathrm{mV}$ and another at $\sim-410 \mathrm{mV}$ (boxes). These positions are close to those expected for native and unfolded Mcc, respectively. The presence of a reduction wave characteristic of unfolded Mcc $(\sim-400 \mathrm{mV})$ for a system containing only the hematite electrode and dissolved Mcc suggests that interaction with the electrode results in unfolding. (c) A derivative of the negative-scan from a voltammogram from Eggleston et al. (2005) that lacks evidence of a reduction wave at $-400 \mathrm{mV}$. Instead, only a reduction wave at $\sim-100 \mathrm{mV}$ is observed (box). All scans were taken at $20 \mathrm{mV} \mathrm{s}^{-1}$.

nevertheless retains bis-his axial heme $\mathrm{Fe}$ coordination. Yeh and Rousseau (1999) find evidence for both bis-his and his-water axial heme coordination at high $(>3 \mathrm{M})$ $\mathrm{GuHCl}$ concentrations.

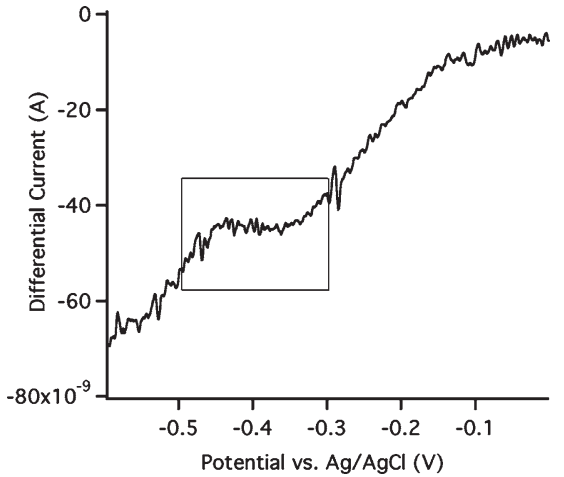

Fig. 4. Derivative trace of the negative-going portion of a $\mathrm{CV}$ scan $\left(10 \mathrm{mV} \mathrm{s}^{-1}\right)$ using a hematite electrode in $10^{-4} \mathrm{M}$ Mcc solution $(100 \mathrm{mM}$ $\mathrm{KCl}, \mathrm{pH}$ 7) showing a peak at about $-400 \mathrm{mV}$, characteristic of unfolded, bis-his or water axial heme coordination.

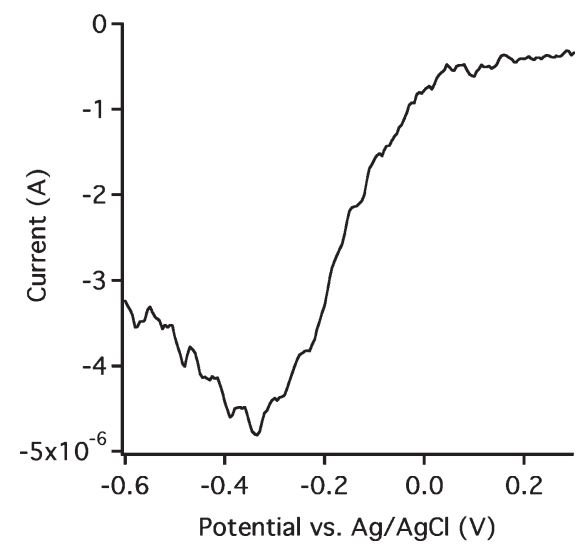

Fig. 5. A differential pulse voltammogram (DPV) of the same set of conditions illustrated in Fig. 4, again showing a peak at about $-400 \mathrm{mV}$ as expected of unfolded Mcc. DPV were taken with a $0.004 \mathrm{~V}$ increment, $0.05 \mathrm{~V}$ pulse amplitude and $0.025 \mathrm{~s}$ pulse width, sampling for $0.0083 \mathrm{~s}$ after pulse, and a $0.2 \mathrm{~s}$ pulse period.

Our denaturation experiment is summarized in Fig. 6. The control experiment (no $\mathrm{Mcc}$ and no $\mathrm{GuHCl}$ ) shows no redox wave in the derivative. The derivative trace with Mcc present, but no $\mathrm{GuHCl}$, shows a reduction wave at $-400 \mathrm{mV}$, characteristic of unfolded Mcc even though no denaturant has yet been added. In Mcc solution with $1 \mathrm{M}$ $\mathrm{GuHCl}$, the dominant features are at $-400 \mathrm{mV}$, as expected for unfolded Mcc in bis-his axial coordination. The inset of Fig. 6 shows the derivative traces for 2 and $3 \mathrm{M} \mathrm{GuHCl}$, which are both noisier than the more dilute solution but which both show redox waves near $-400 \mathrm{mV}$, again as expected for unfolded Mcc (we found that $\mathrm{CV}$ at higher $\mathrm{GuHCl}$ concentrations was always noisier than without $\mathrm{GuHCl}$, though no redox waves attributable to $\mathrm{GuHCl}$ were observed). The surprising result, however, is that redox waves for unfolded Mcc occur before any denaturant is added, suggesting either that interaction with or sorption to the hematite electrode surface results in a conformation change akin to that induced by denaturant or that some of the Mcc in solution is in an unfolded state before adsorption. 


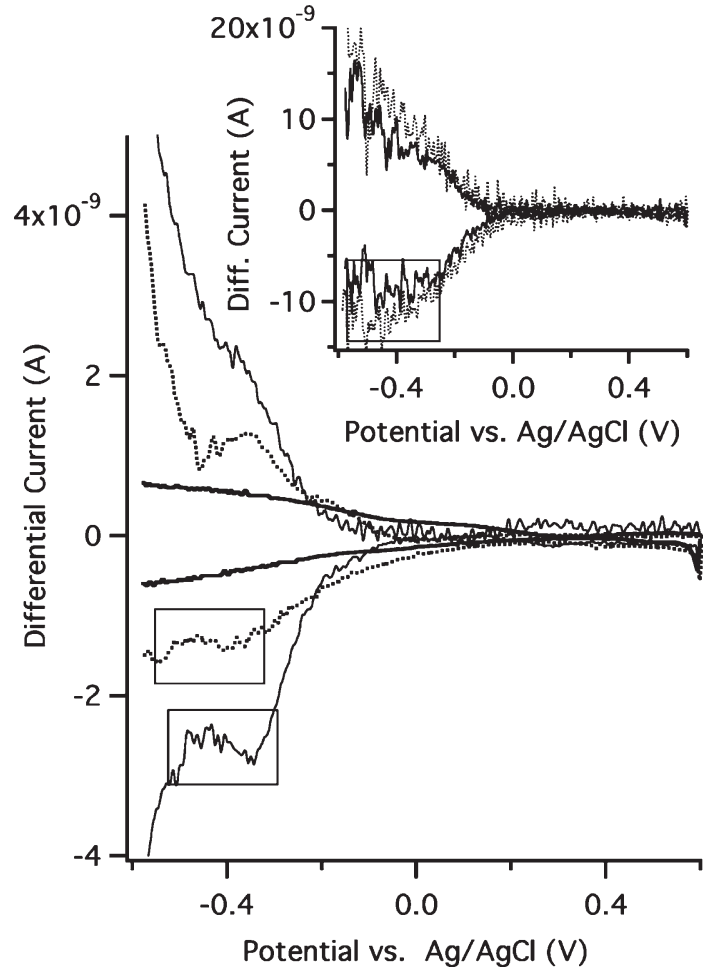

Fig. 6. Derivative traces from $\mathrm{CV}$ scans using a hematite electrode in $100 \mathrm{mM} \mathrm{KCl}(\mathrm{pH} \sim 7$ ) solution (heavy solid), $100 \mathrm{mM} \mathrm{KCl}$ solution with $10^{-4} \mathrm{M}$ Mcc (dotted), and $100 \mathrm{mM} \mathrm{KCl}$ with $10^{-4} \mathrm{M}$ Mcc and $1 \mathrm{M}$ $\mathrm{GuHCl}$ (thin solid). The inset shows the derivative traces with $2 \mathrm{M}$ (dotted) and $3 \mathrm{M}$ (solid) $\mathrm{GuHCl}$. All $\mathrm{CV}$ scans started at $+0.6 \mathrm{~V}$ vs. $\mathrm{Ag} / \mathrm{AgCl}$ and were taken at $20 \mathrm{mV} \mathrm{s}^{-1}$. Although control scans without Mcc showed no redox peaks, data were noisier at higher $\mathrm{GuHCl}$ concentrations (leading to noisy differential results such as in the inset).

\subsection{Electrochemistry of Mcc using ITO electrodes}

Fig. 7 shows some CV scans using an ITO electrode in an experiment directly analogous to that illustrated in Fig. 6 for hematite electrodes. Fig. 7a shows two control scans, one for Mcc solution with no $\mathrm{GuHCl}$ and the other for $3 \mathrm{M} \mathrm{Gu} \mathrm{HCl}$ with no Mcc, along with $\mathrm{CV}$ for Mcc solution with $3 \mathrm{M} \mathrm{GuHCl}$. Both the native $\mathrm{Mcc} \mathrm{CV}$ and the $\mathrm{CV}$ for $3 \mathrm{M} \mathrm{GuHCl} / \mathrm{Mcc}$ solution show a reduction wave characteristic of native Mcc. For the native Mcc solution, the derivative inset of Fig. 7a shows evidence of a reduction wave at a potential characteristic of unfolded Mcc (box) in addition to the larger peak characteristic of native Mcc. The CV scan for $3 \mathrm{M} \mathrm{GuHCl}$, of course, shows a much larger wave for unfolded Mcc. The importance of timing is illustrated by Fig. 7b, in which the cathodic current at $-420 \mathrm{mV}$ is given for different $\mathrm{GuHCl}$ concentrations, along with arrows showing the sequence in which the measurements were made. When we ran the scans for $5 \mathrm{M} \mathrm{GuHCl}$ and repeated the scan for $6 \mathrm{M} \mathrm{GuHCl}$ (Fig. 7b), we got much less cathodic current than in our initial scans at $6 \mathrm{M} \mathrm{GuHCl}$. The current associated with the reduction wave is evidently highly dependent on when the $\mathrm{CV}$ scan is taken. Sorption experiments in the presence of $\mathrm{GuHCl}$ show that the amount of Mcc adsorbed to hematite
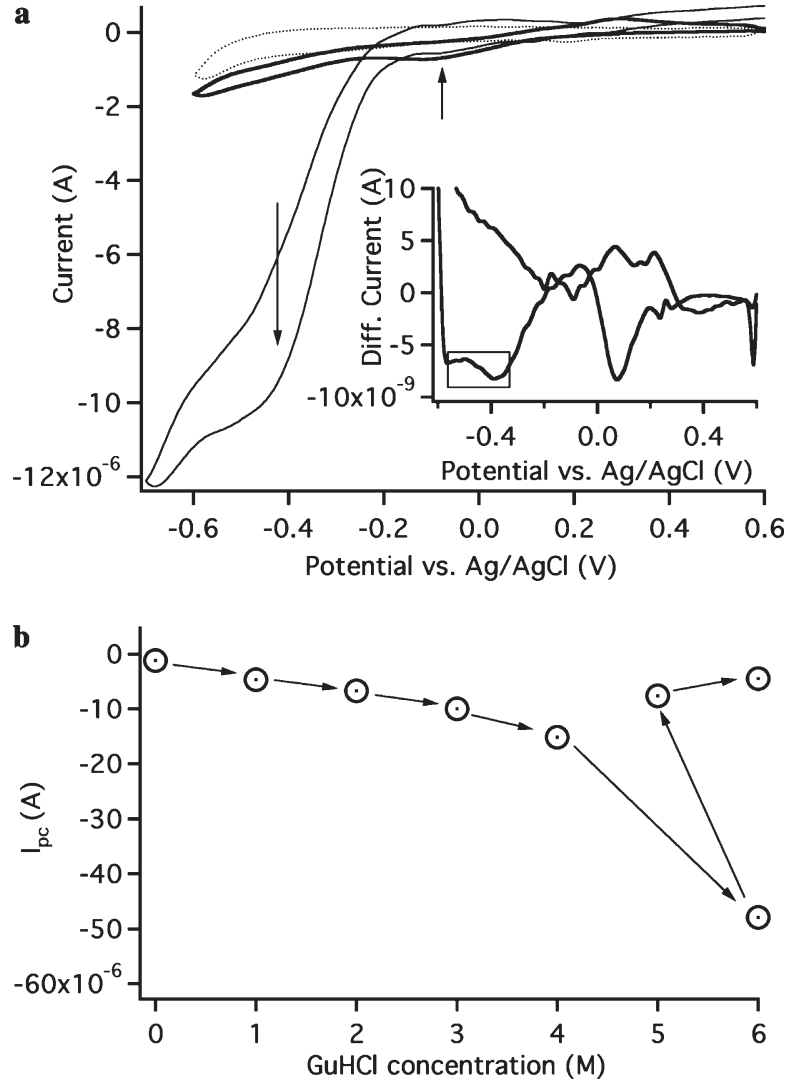

Fig. 7. (a) Control $\mathrm{CV}$ scans ( $\mathrm{pH} \mathrm{7}$, using an ITO electrode, $20 \mathrm{mV} \mathrm{s}^{-1}$ ) with $10^{-4} \mathrm{M}$ Mcc but no $\mathrm{GuHCl}$ (thick solid) and with $3 \mathrm{M} \mathrm{GuHCl}$ but with no Mcc (thin dotted) together with a CV scan for $10^{-4} \mathrm{M}$ Mcc with $3 \mathrm{M} \mathrm{GuHCl}$. Comparison of the $\mathrm{CV}$ without $\mathrm{GuHCl}$ to that with $3 \mathrm{M}$ $\mathrm{GuHCl}$ and $\mathrm{Mcc}$ shows that the $3 \mathrm{M} \mathrm{GuHCl}$ case still retains some evidence of the presence of native Mcc (short upward arrow). The largest current wave, however, occurs at a potential characteristic of unfolded Mcc (long downward arrow). Inset: Derivative of the scan of Mcc solution (no $\mathrm{GuHCl}$ ) in (a), showing evidence of a wave at about $-400 \mathrm{mV}$, characteristic of unfolded Mcc. (b) Cathodic current at $-420 \mathrm{mV}$ (similar to that in (a), long downward arrow) vs. $\mathrm{Ag} / \mathrm{AgCl}$ plotted as a function of $\mathrm{GuHCl}$ concentration. Arrows indicate the order in which experiments were done.

decreases with increasing $\mathrm{GuHCl}$ concentration (data not shown), so one qualitative interpretation is that after the $\mathrm{GuHCl}$ concentration is increased, it takes some time for protein to desorb so that a decreasing current is observed with time. With no $\mathrm{GuHCl}$, however, the time effect is different. The most prominent reduction wave in another experiment with a different ITO electrode (Fig. 8) is at a potential characteristic of unfolded Mcc. The reason that native Mcc appears dominant in Fig. 7 but unfolded Mcc appears dominant in Fig. 8 is unknown, but we speculate that the difference can be partly explained through time-dependent phenomena- that is, one electrode may have been exposed to protein longer than the other (e.g., see Hill et al., 1997; Calonder et al., 2001).

This point is emphasized in Fig. 9, a series of ten CV scans were taken in succession (in this case, at $\mathrm{pH}$ 9). With each scan the cathodic currents associated with reduction of Mcc by the ITO electrode decreases. This reflects a 


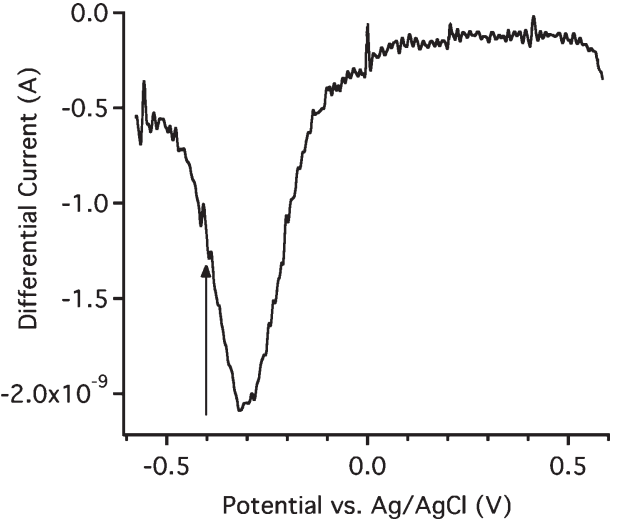

Fig. 8. Derivative trace of a $\mathrm{CV}$ scan $\left(20 \mathrm{mV} \mathrm{s}^{-1}\right)$ taken with an ITO electrode and $10^{-4} \mathrm{M}$ Mcc solution. The most prominent reduction wave is at about $-400 \mathrm{mV}$ vs. $\mathrm{Ag} / \mathrm{AgCl}$ (arrow).

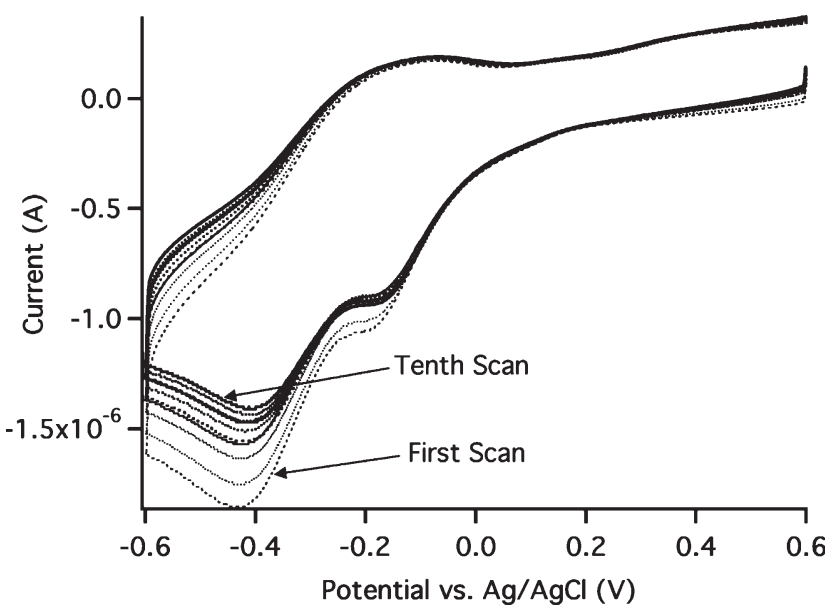

Fig. 9. A series of $10 \mathrm{CV}$ scans $\left(50 \mathrm{mV} \mathrm{s}^{-1}\right.$ scan rate) taken using an ITO electrode and $10^{-4} \mathrm{M}$ Mcc solution at $\mathrm{pH} 9$ (adjusted with $10 \mathrm{mM} \mathrm{KOH}$ ). Lines become more densely dotted and heavier with time. At this $\mathrm{pH}$, some of the Mcc molecules have lost the $695 \mathrm{~nm}$ absorption band characteristic of histidine-methionine axial heme Fe coordination. Therefore, some of the Mcc is in an unfolded state $(-400 \mathrm{mV}$ reduction potential) and some remains in a native conformation.

steady decrease in the total amount of protein available to be reduced with time, possibly because the electrode becomes "blocked" with denatured and electroinactive protein over time. Also in Fig. 9, as with Fig. 7, the reduction (cathodic) currents are not balanced by an equivalent (anodic) oxidation wave. The relative lack of anodic current is usually attributed to the rectifying properties of semiconductor electrodes (for $n$-type semiconductors, potentials positive of the flat band potential lead to upward band bending at the surface and thus to a "blocking" space charge layer that inhibits current exchange; e.g., see Morrison, 1980). While this is part of the picture, it does not explain the rapid rise in cathodic currents with increasing denaturant concentration. This asymmetry can be interpreted as the result of oxidation of the Mcc by a secondary oxidant after it is reduced at the working electrode. Although residual oxygen in our electrochemical chamber is a possibility, we have taken care to minimize oxygen contamination and thus oxygen is unlikely to have such dramatic effects. Another strong possibility is that protein molecules more distant from the electrode than those initially reduced at the electrode, whether native or unfolded, can act as secondary oxidants. Fig. 10 illustrates how electrons could flow from the hematite electrode to unfolded Mcc on the electrode surface, and then to native Mcc (which is more oxidizing). It is also possible for electrons to flow from an unfolded Mcc molecule on the electrode surface to another unfolded Mcc molecule that is further from the surface.

\subsection{Current vs. time: electron transfer triggered by conformation change}

If the pathway illustrated in Fig. 10 is plausible, we hypothesize further that reduced native Mcc will unfold upon sorption to a clean hematite electrode surface and, in so doing, trigger electron transfer to the hematite electrode to produce an anodic current transient. The electrode should then be coated with unfolded protein, inhibiting further electrochemical interaction between native protein in solution and the electrode.

To test this hypothesis, we held the hematite electrode potential at $-200 \mathrm{mV}$ vs. $\mathrm{Ag} / \mathrm{AgCl}$. At this potential, the hematite should be able to oxidize molecules of reduced unfolded Mcc (but should not be able to oxidize molecules of reduced native $\mathrm{Mcc}$ ) and should also still be able to reduce molecules of native oxidized Mcc (Fig. 10). This potential is also slightly negative of the hematite flatband potential at near-neutral pH (e.g., Sanchez et al., 1988) so that there should be no Schottky barrier to electron exchange. In this experiment, the starting solution was a

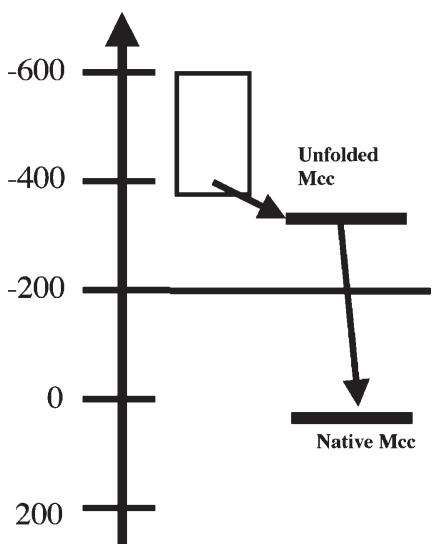

Fig. 10. Schematic energy-level diagrams showing how electrons transferred from the hematite electrode (conduction band) at negative potential (box) to unfolded Mcc (bar) can then in turn reduce native Mcc (bar) and thus be available to be reduced by more electrons from the electrode. The diagram also shows that unfolded reduced Mcc is energetically uphill from a hematite electrode held at $-200 \mathrm{mV}$ vs. $\mathrm{Ag} / \mathrm{AgCl}$ (yellow box), whereas native oxidized $\mathrm{Mcc}$ is able to accept electron from the electrode at $-200 \mathrm{mV}$. 
$100 \mathrm{mM} \mathrm{KCl}$ solution in contact with the hematite electrode held at $-200 \mathrm{mV}$ vs. $\mathrm{Ag} / \mathrm{AgCl} .50 \mu \mathrm{L}$ of the mixed reduced and oxidized Mcc solution was injected into the electrochemical cell while current was monitored. Results are shown in Fig. 11.

The background current is cathodic because, in order to be ready to inject the Mcc solution, we had to open the cell slightly so that a small amount of oxygen probably contaminated the electrochemical cell. Upon the first injection of solution containing both reduced and oxidized Mcc, however, a large anodic current spike is observed. The transient lasts 6 to $7 \mathrm{~s}$, which is the same time scale as the rapid initial adsorption of Mcc to oxide electrodes (Tie et al., 2003) and is much longer than the current transients associated with solution injection and mixing (without Mcc) in control experiments (data not shown), which are comparable to the small transient at the point of the second injection in Fig. 11. The total charge that passes during the anodic transient (above baseline) upon the first injection is about 3 orders of magnitude less than the total amount of reduced Mcc in the injected solution aliquot, so the transient can be explained by a minority of the reduced Mcc interacting with the electrode during the experiment. The amount of current that passes during the transient is about an order of magnitude greater than a close-packed monolayer of Mcc on the electrode area, however, suggesting either that the close-packed spheres assumption does not hold for Mcc (perhaps because of unfolding) or that there is exchange of Mcc with solution during the transient.

This experiment is consistent with the interpretation that the initial Mcc that encounters the electrode unfolds upon sorption, becoming more reducing in the process and therefore transferring electrons to the hematite electrode. After the initial Mcc sorbs and unfolds, however, an armoring protein layer is created such that further Mcc molecules

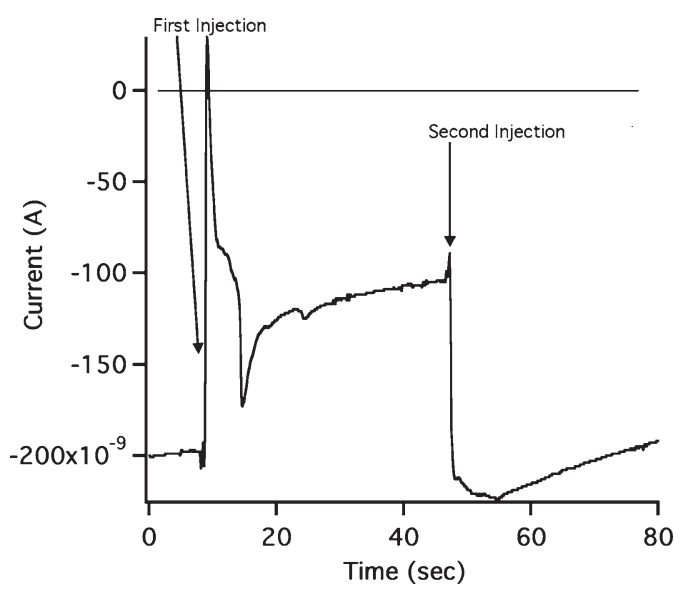

Fig. 11. Current vs. time during an experiment in which a mixture of reduced and oxidized Mcc is injected at two different times into the electrochemical cell. The first injection resulted in a strong anodic current transient, whereas the second injection did not. This is consistent with the idea that the initial Mcc that interacts with the electrode surface unfolds as it sorbs and then remains on the surface as a coating that partially "blocks" the electrode from interaction with further Mcc. that approach the electrode surface are "held" at a greater distance (resulting in lower currents). Those that do undergo redox processes near the electrode do not unfold upon interaction with previously sorbed protein and thus appear electrochemically native. This result is consistent with that of Hill et al. (1997) for glassy carbon electrodes.

\subsection{The 10.1 kDa monoheme cytochrome from Acidiphilium cryptum}

We also studied a $10.1 \mathrm{kDa}$ monoheme cytochrome from Acidiphilium cryptum (Fig. 12). This protein exhibits histidine-methionine axial $\mathrm{Fe}$ coordination (on the basis of the
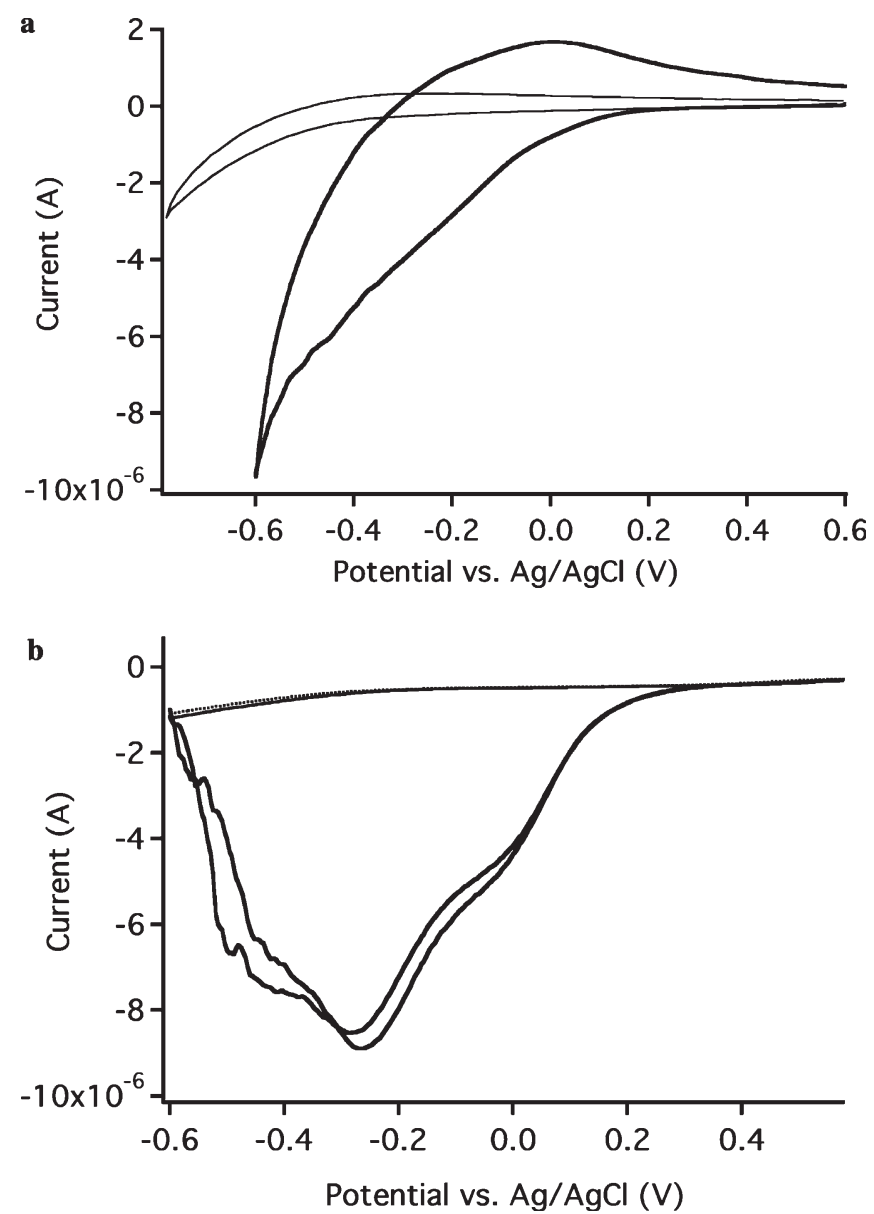

Fig. 12. (a) Control CV of the hematite electrode in $10 \mathrm{mM} \mathrm{KCl}$ solution in a nitrogen-purged electrochemical cell (thin solid) together with a $\mathrm{CV}$ taken in the presence of the $10.1 \mathrm{kDa}$ protein (thick solid). (b) Differential pulse voltammetry (DPV) of the $10.1 \mathrm{kDa}$ cytochrome from A. cryptum (thick solid lines represent repeat voltammograms taken within a few minutes of each other). Control differential pulse voltammograms (DPV) taken in DDI water (dashed) and in $10 \mathrm{mM} \mathrm{KCl}$ (thin solid). Three subpeaks indicate that there are at least three different reduction potentials represented in the sample, indicating that there are at least three different conformational states of this monoheme protein present in the vicinity of the hematite electrode surface. The second DPV scan with the cytochrome shows greater current at low potential than the first scan. DPV were taken with a $0.004 \mathrm{~V}$ increment, $0.05 \mathrm{~V}$ pulse amplitude and $0.025 \mathrm{~s}$ pulse width, sampling for $0.0083 \mathrm{~s}$ after pulse, and a $0.2 \mathrm{~s}$ pulse period. 
presence of a weak absorption band at $695 \mathrm{~nm}$ ), and is probably a periplasmic protein cytochrome in A. cryptum and thus not involved in direct cell-to-solid electron transfer (though a role in reduction of soluble iron, which is more prevalent for acidophiles, remains more probable).

In Fig. 12a, the CV is clearly very different from the control CV from both $10 \mathrm{mM} \mathrm{KCl}$ and DDI water, but individual peaks cannot easily be discerned. We therefore configured the potentiostat for DPV (Fig. 12b). The resulting voltammograms show at least three separate reduction waves in the potential region from zero to $-450 \mathrm{mV}$ vs. $\mathrm{Ag} / \mathrm{AgCl}$. A reduction wave at about $0 \mathrm{mV}$ is similar to the $E_{\mathrm{pc}}$ of Mcc (remembering that the overall scan rate in DPV is much slower than in the CV scans) and can thus be interpreted as a "native" globular his-met conformational state. The more negative reduction potentials might be either his-his coordinated heme or his-water coordinated heme (Tezcan et al., 1998; Chen et al., 2002). Although the conformational states of this protein in solution are not yet known, a monoheme cytochrome can only exhibit different $E^{0^{\prime}}$ values if different individual molecules in the population of molecules being addressed electrochemically in Fig. 12 have different conformational states.

The second DPV scan shows greater current at the lowest of the three potentials, and less current at the two more positive potentials. We have observed this phenomenon in other cytochromes from DIRB, including known outermembrane cytochromes, as well (this will be the subject of a future paper). One interpretation is that electrons transferred into the cytochrome on the first scan slowly "cascade" down in energy by transferring from more reducing cytochromes to less reducing ones, resulting in less current at higher potentials on the subsequent scan. This does not explain why more current to the cytochrome at low potential occurs on the second scan, however. We speculate that, instead, some of the cytochromes respond to the reducing conditions imposed by the first scan by reconforming to a more reducing conformational state.

\section{Conclusions}

Direct electrochemistry of Mcc using hematite electrodes exhibits evidence for the existence of both "native" and unfolded conformations of Mcc near the electrode surface. The unfolded state of Mcc is more reducing than the native state. A mixture of reduced and oxidized Mcc, when injected into an electrochemical cell containing a hematite electrode held at $-200 \mathrm{mV}$ vs. $\mathrm{Ag} / \mathrm{AgCl}$ (a potential reducing toward native Mcc but oxidizing toward reduced unfolded $\mathrm{Mcc}$ ) results in anodic current (from the cytochrome to the hematite) on the first injection, but not on a subsequent injection. This current is only possible from reduced and unfolded Mcc, and is interpreted as Mcc unfolding as it coats and "blocks" the hematite electrode such that subsequent Mcc does not interact with a clean hematite electrode surface. This shows that adsorption of the Mcc to the clean hematite electrode likely results in conformation change that makes the protein more reducing and that promotes electron transfer from reduced cytochrome to the oxide. A similar phenomenon could occur with outer-membrane multiheme cytochromes associated with DIRB, although it is also likely that the behavior of these proteins is more complex than that of the cytochromes studied here because of the many different redox cofactors involved. We show that a $10.1 \mathrm{kDa}$ monoheme cytochrome from Acidiphilium cryptum exhibits evidence for at least three different conformational states when interacting with a hematite electrode.

The data presented here are interpreted on the basis of a well-established relationship between redox behavior and conformational state for Mcc. Other data are in agreement with this interpretation. The slab-optical waveguide study by Matsuda et al. (2003), for example, shows a negative shift in $E^{0^{\prime}}$ of Mcc recorded on the basis of the optical absorption spectrum of Mcc adsorbed on an ITO electrode. We have also gathered X-ray absorption spectroscopy data (XANES and EXAFS) that corroborate the idea that Mcc unfolds when it interacts with oxide surfaces. This data will be the subject of a forthcoming paper.

As has been shown previously, the observation of direct electrochemistry of Mcc depends crucially on the properties of the electrode surface; "native" redox potentials are often observed even though the electrode surface is coated with unfolded, and possibly electroinactivated, protein. If an adsorption-triggered conformation change is part of the operation of outer-membrane cytochromes from DIRB, however, we would expect that the adsorption-induced conformation change is reversible, unlike Mcc.

\section{Acknowledgments}

We gratefully acknowledge support from the National Science Foundation (EAR-0434019 to Eggleston and Magnuson) and Pacific Northwest National Laboratory (Biogeochemistry Grand Challenge to Eggleston). We thank the Universitaet zu Koeln Mineralogical Museum and Dr. Guntram Jordan for generously providing the conductive hematite that was used as an electrode. We thank two anonymous reviewers and Associate Editor Dr. Wogelius for constructive criticism that was very helpful in improving the manuscript.

Associate editor: Roy A. Wogelius

\section{References}

Albrechtsen, H.-J., Christensen, T.H., 1994. Evidence for microbial iron reduction in landfill leachate-polluted aquifer (Vejen, Denmark). Appl. Environ. Microbiol. 60, 3920-3925.

Beliaev, A.S., Saffarini, D.A., 1998. Shewanella putrefaciens mtrB encodes an outer membrane protein required for $\mathrm{Fe}(\mathrm{III})$ and $\mathrm{Mn}(\mathrm{IV})$ reduction. J. Bacteriol. 180, 6292-6297.

Boschloo, G., Fitzmaurice, D., 1999. Spectroelectrochemistry of highly doped nanostructured tin dioxide electrodes. J. Phys. Chem. B 103, 3093-3098. 
Bowden, E.F., Hawkridge, F.M., Blount, H.N., 1984. Interfacial electrochemistry of cytochrome $c$ at tin oxide, indium oxide, gold, and platinum electrodes. J. Electroanal. Chem. 161, 355-376.

Calonder, C., Tie, Y., Van Tassel, P.R., 2001. History dependence of protein adsorption kinetics. Proc. Natl. Acad. Sci. USA 98, 10664 10669.

Chen, X., Ferrigno, R., Yang, J., Whitesides, G.M., 2002. Redox properties of cytochrome $c$ adsorbed on self-assembled monolayers: a probe for protein conformation and orientation. Langmuir 18, 70097015.

Cruciat, C.-M., Brunner, S., Baumann, F., Neupert, W., Stuart, R.A., 2000. The cytochrome $b c_{1}$ and cytochrome coxidase complexes associate to form a single supracomplex in yeast mitochondria. $J$. Biol. Chem. 275, 18093-18098.

Cummings, D.E., Snoeyenbos-West, O.L., Newby, D.T., Niggemyer, A.M., Lovley, D.R., Achenbach, L.A., Rosenzweig, R.F., 2003. Diversity of Geobacteraceae species inhabiting metal-poluted freshwater lake sediments ascertained by $16 \mathrm{~S}$ rDNA analyses. Microb. Ecol. 46, 257-269.

Dick, L.A., Haes, A.J., Van Duyne, R.P., 2000. Distance and orientation dependence of heterogeneous electron transfer: a surface-enhanced resonance Raman scattering study of cytochrome $c$ bound to carboxylic acid terminated alkanethiols adsorbed on silver electrodes. J. Phys. Chem. 104, 11752-11762.

DiChristina, T.J., Moore, C.M., Haller, C.A., 2002. Dissimilatory Fe(III) and $\mathrm{Mv}(\mathrm{IV})$ reduction by Shewanella putrefaciens requires ferE, a homolog of the pulE (gspE) type II protein secretion gene. J. Bacteriol. 184, 142-151.

Eddowes, M.J., Hill, H.A.O., 1977. Novel method for the investigation of the electrochemistry of metalloproteins: cytochrome c. J. Chem. Soc. Chem. Commun. 1977, 771-772.

Eggleston, C.M., Khare, N., Lovelace, D., 2005. Cytochrome $c$ interaction with hematite $\left(\alpha-\mathrm{Fe}_{2} \mathrm{O}_{3}\right)$ surfaces. J. Electron Spectrosc. 50, 220-227.

Eggleston, C.M., Stack, A.G., Rosso, K.M., Higgins, S.R., Bice, A.M., Boese, S.W., Pribyl, R.D., Nichols, J.J., 2003. The structure of hematite $\left(\alpha-\mathrm{Fe}_{2} \mathrm{O}_{3}\right)$ (001) surfaces in aqueous media: scanning tunneling microscopy and resonant tunneling calculations of coexisting $\mathrm{O}$ and $\mathrm{Fe}$ terminations. Geochim. Cosmochim. Acta $\mathbf{6 7}$, 985-1000.

Gaspard, S., Vazquez, F., Holliger, C., 1998. Localization and solubilization of the iron(III) reductase of Geobacter sulfurreducens. Appl. Environ. Microbiol. 64 (9), 3188-3194.

Hildebrandt, P., Stockburger, M., 1989. Cytochrome $c$ at charged interfaces. 1. Conformation and redox equilibria at the electrode/ electrolyte interface probed by surface-enhanced resonance raman spectroscopy. Biochemistry 28, 6710-6721.

Hill, H.A.O., Hunt, N.I., Bond, A.M., 1997. The transient nature of the diffusion-controlled component of the electrochemistry of cytochrome $c$ at "bare" gold electrodes: an explanation based on a self-blocking mechanism. J. Electroanal. Chem. 436, 17-25.

Keilin, D., 1925. On cytochrome, a respiratory pigment, common to animals, yeast, and higher plants. Proc. R. Soc. Lond. B Biol. Sci. 98, 312-339.

Lange, C., Hunte, C., 2002. Crystal structure of the yeast cytochrome $b c_{1}$ complex with its bound substrate cytochrome c. Proc. Natl. Acad. Sci. USA 99, 2800-2805.

Liu, C., Gorby, Y.A., Zachara, J.M., Fredrickson, J.K., Brown, C.F., 2002. Reduction kinetics of Fe(III), Co(III), U(I), Cr(VI), and Tc(VIII) in cultures of dissimilatory metal-reducing bacteria. Biotechnol. Bioeng. 80, 637-649.

Lloyd, J.R., Sole, V.A., Van Praagh, C.V.G., Lovley, D.R., 2000. Direct and $\mathrm{Fe}(\mathrm{II})$-mediated reduction of technetium by $\mathrm{Fe}(\mathrm{III})$-reducing bacteria. Appl. Environ. Microbiol. 66, 3743-3749.

Lloyd, J.R., Livens, F.R., Lovley, D.R., Chesnes, J., Glasauer, S., Bunker, D.J., 2002. Reduction of actinides and fission products by $\mathrm{Fe}(\mathrm{III})$ reducing bacteria. Geomicrobiol. J. 19, 103-120.

Lovley, D.R., 1991. Dissimilatory $\mathrm{Fe}(\mathrm{III})$ and $\mathrm{Mn}(\mathrm{IV})$ reduction. Microbiol. Rev. 55, 259-287.
Lovley, D.R., 2002. Dissimilatory metal reduction: fom early life to bioremediation. ASM News 68, 231-237.

Lovley, D.R., Phillips, E.J.P., 1994. Reduction of chromate by Desulfovibrio vulgaris (Hildenborough) and its $c_{3}$ cytochrome. Appl. Environ. Microbiol. 60, 726-728.

Magnuson, T.S., Isoyama, N., Hodges-Myerson, A.L., Davidson, G., Maroney, M.J., Geesey, G.G., Lovley, D.R., 2001. Isolation, characterization and gene sequence analysis of a membraneassociated $89 \mathrm{kDa} \mathrm{Fe}(\mathrm{III})$ reducing cytochrome $c$ from Geobacter sulfurreducens. Biochem. J. 359, 147-152.

Margoliash, E., Ferguson-Miller, S., Tulloss, J., Kang, C.H., Feinberg, A., Brautigan, D.L., Morrison, M., 1973. Separate intramolecular pathways for reduction and oxidation of cytochrome $c$ in electron transport chain reactions. Proc. Natl. Acad. Sci. USA 70, 3245-3249.

Matsuda, N., Santos, J.H., Takatsu, A., Kato, K., 2003. Spectroelectrochemical studies on surface immobilized cytochrome $c$ on ITO electrode by slab optical waveguide spectroscopy. Thin Solid Films 438-439, 403-406.

Mehta, T., Coppi, M.V., Childers, S.E., Lovley, D.R., 2005. Outer membrane $c$-type cytochromes required for $\mathrm{Fe}(\mathrm{III})$ and $\mathrm{Mn}(\mathrm{IV})$ oxide reduction in Geobacter sulfurreducens. Appl. Environ. Microbiol. 71, 8634-8641.

Moore, G.R., Pettigrew, G.W., 1990. Cytochromes c: Evolutionary, Structural, and Physicochemical Aspects. Springer-Verlag, New York.

Morrison, S.R., 1980. Electrochemistry at Semiconductor and Oxidized Metal Electrodes. Plenum Press, New York, 401 pp.

Myers, C.R., Myers, J.M., 1993. Ferric reductase is associated with the membranes of anaerobically grown Shewanella putrefaciens MR-1. FEMS Microbiol. Lett. 108, 15-22.

Myers, C.R., Myers, J.M., 1997. Cloning and sequence of cymA, a gene encoding a tetraheme cytochrome $c$ required for reduction of iron(III), fumarate, and nitrate by Shewanella putrefaciens MR-1. J. Bacteriol. 179, $1143-1152$.

Myers, J.M., Myers, C.R., 2002. Genetic complementation of an outer membrane cytochrome omcB mutant of Shewanella putrefaciens MR-1 requires omcB plus downstream DNA. Appl. Environ. Microbiol. 68 (6), 2781-2793.

Myers, C.R., Myers, J.M., 2003. Cell surface exposure of the outer membrane cytochromes of Shewanella oneidensis MR-1. Lett. Appl. Microbiol. 37, 254-258.

Oellerich, S., Wackerbarth, H., Hildebrandt, P., 2002. Spectroscopic characterization of non-native conformational states of cytochrome c. J. Phys. Chem. B 106, 6566-6580.

Pettigrew, G.W., Moore, G.R., 1987. Cytochromes c: Biological Aspects. Springer-Verlag, New York.

Pilloud, D.L., Chen, X., Dutton, P.L., Moser, C.C., 2000. Electrochemistry of self-assembled monolayers of iron protoporphyrin IX attached to modified gold electrodes through thioether linkage. J. Phys. Chem. B 104, 2868-2877.

Pinheiro, T.J.T., 1994. The interaction of horse heart cytochrome $c$ with phospholipids bilayers. Structural and dynamic effects. Biochimie 76, 489-500.

Pitts, K.E., Dobbin, P.S., Reyes-Ramirez, F., Thomson, A.J., Richardson, D.J., Seward, H.E., 2003. Characterization of the Shewanella oneidensis MR-1 decaheme cytochrome MtrA. J. Biol. Chem. 278, 27758-27765.

Richardson, D.J., 2000. Bacterial respiration: a flexible process for a changing environment. Microbiology 146, 551-571.

Sanchez, C., Sieber, K.D., Somorjai, G.A., 1988. The photoelectrochemistry of niobium doped $\alpha-\mathrm{Fe}_{2} \mathrm{O}_{3}$. J. Electroanal. Chem. 252, 269-290.

Schagger, H., von Jagow, G., 1987. Tricine-sodium dodecyl sulfatepolyacrylamide gel electrophoresis for the separation of proteins in the range from 1 to $100 \mathrm{kDa}$. Anal. Biochem. 166, 368-379.

Stack, A.G., Eggleston, C.M., Engelhard, M.H., 2004. Reaction of hydroquinone with hematite I: study of adsorption behavior by electrochemical scanning tunneling microscopy and X-ray photoelectron spectroscopy. J. Coll. Interf. Sci. 274, 433-441. 
Tezcan, F.A., Winkler, J.R., Gray, H.B., 1998. Effects of ligation and folding on reduction potentials of heme proteins. J. Am. Chem. Soc. 120, 13383-13388.

Theorell, H., Akesson, A., 1941a. Studies on cytochrome $c$. I. Electrophoretic purification of cytochrome $c$ and its amino acid composition. J. Am. Chem. Soc. 63, 1804-1811.

Theorell, H., Akesson, A., 1941b. Studies on cytochrome $c$. II. The optical properties of pure cytochrome $c$ and some of its derivatives. J. Am. Chem. Soc. 63, 1812-1818.

Theorell, H., Akesson, A., 1941c. Studies on cytochrome $c$. III. Titration curves. J. Am. Chem. Soc. 63, 1818-1820.

Theorell, H., Akesson, A., 1941d. Studies on cytochrome $c$. IV. The magnetic properties of ferric and ferrous cytochrome $c$. J. Am. Chem. Soc. 63, 1820-1827.

Thomas, P.E., Ryan, D., Levin, W., 1976. An improved staining procedure for the detection of the peroxidase activity of cytochrome P-450 on sodium dodecyl sulfate-polyacrylamide gels. Anal. Biochem. 75, 168-176.

Thomas, Y.G., Goldbeck, R.A., Kliger, D.S., 2000. Characterization of equilibrium intermediates in denaturant-induced unfolding of ferrous and ferric cytochromes $c$ using magnetic circular dichroism, circular dichroism, and optical absorption spectroscopies. Biopolymers 57, 29-36.

Tie, Y., Calonder, C., Van Tassel, P.R., 2003. Protein adsorption: kinetics and history dependence. J. Coll. Interf. Sci. 268, 1-11.

Williams, P.A., Fülöp, V., Garman, E.F., Saunders, N.F.W., Ferguson, S.J., Hajdu, J., 1997. Haem-ligand switching during catalysis in crystals of a nitrogen-cycle enzyme. Nature 389, 406-412.

Witt, H., Malatesta, F., Nicoletti, F., Brunori, M., Ludwig, B., 1998. Cytochrome-c-binding site on cytochrome oxidase in Paracoccus denitrificans. Eur. J. Biochem. 251, 367-373.

Xu, J.-J., Peng, Y., Liu, S.-Q., Chen, H.Y., 2004. Direct electrochemistry of cytochrome $c$ on EDTA-Z $\mathrm{ZrO}_{2}$ organic-inorganic hybrid film modified electrodes. Chinese J. Chem. 22, 1403-1406.

Yeh, P., Kuwana, T., 1977. Reversible electrode reaction of cytochrome $c$. Chem. Lett. 1977, 1145-1148.

Yeh, S.-R., Rousseau, D.L., 1999. Ligand exchange during unfolding of cytochrome $c$. J. Biol. Chem. 274, 17853-17859. 